\begin{tabular}{|l|l|l|}
\hline \multicolumn{2}{|c|}{ PublisherInfo } \\
\hline \hline PublisherName & $:$ & BioMed Central \\
\hline \hline PublisherLocation & $:$ & London \\
\hline \hline PublisherImprintName & $:$ & BioMed Central \\
\hline \hline
\end{tabular}

\title{
Pulmonary Artery Catheter Education Project
}

\begin{tabular}{|c|c|c|c|}
\hline \multicolumn{4}{|c|}{ ArticleInfo } \\
\hline ArticleID & : & 2909 & \\
\hline ArticleDOI & : & $10.1186 / \operatorname{cc} 2830$ & \\
\hline ArticleSequenceNumber & : & 7 & \\
\hline ArticleCategory & : & Web report & \\
\hline ArticleFirstPage & : & 1 & \\
\hline ArticleLastPage & : & 4 & \\
\hline ArticleHistory & : & $\begin{array}{l}\text { RegistrationDat } \\
\text { Received } \\
\text { Accepted } \\
\text { OnlineDate }\end{array}$ & $\begin{array}{l}: \text { 2004-2-6 } \\
: 2004-2-6 \\
: \quad 2004-02-10 \\
: 2004-2-27\end{array}$ \\
\hline ArticleCopyright & : & BioMed Central & d2004 \\
\hline ArticleGrants & • & & \\
\hline ArticleContext & : & 13054 & \\
\hline
\end{tabular}


Niall D Ferguson, Aff1

Corresponding Affiliation: Aff1

Email: n.ferguson@utoronto.ca

Affl Assistant Professor, Department of Medicine, Division of Respirology, and Interdepartmental Division of Critical Care Medicine, University Health Network, University of Toronto, Ontario, Canada

\section{Keywords}

cardiac output, catheterization, pulmonary wedge pressure, Swan-Ganz

\section{Abbreviations}

\section{PA}

pulmonary artery.

The Pulmonary Artery Catheter Education Project is a collaborative effort designed to "provide a state-of-the-art educational program on how to use the pulmonary artery catheter in the clinical environment". This online educational tool is endorsed by a number of national and international professional organizations, including the American Thoracic Society, the Society of Critical Care Medicine, and the American Association of Critical Care Nurses.

The website is organized into individual lessons, each focusing on a specific aspect of pulmonary artery (PA) catheter use and interpretation. Each lesson is comprised of a list of learning objectives, a pretest, a narrated slide presentation, mini case studies in some lessons, and a post-test. Lessons are grouped in clusters of five or six according to the level of expertise. Although the home page states that topics are divided into four levels, only two levels are currently available: Fundamental Hemodynamic Information I and Fundamental Hemodynamic Information II. It is unclear whether the addition of other lessons is still planned. Upon completion of each lesson, users can register for American continuing medical or nursing education credits for a nominal fee.

The six lessons in Level I are aimed at newcomers to the PA catheter and cover basics of hemodynamic physiology, interpretation of usual hemodynamic waveforms, and therapeutic interventions in straightforward clinical situations. This level seems appropriate for physicians, nurses, and respiratory therapists who are just becoming familiar with the PA catheter.

Level II is aimed at a more advanced audience and covers all of the same general topics as Level I but at a more sophisticated level. This level is probably suited to senior residents or fellows in critical care medicine or anesthesia, or to nurses or respiratory therapists with advanced hemodynamic monitoring skills. Objectives upon completion of the lessons in Level II range from the ability to recognize abnormal values of cardiac index, stroke volume and mixed venous saturation, to the ability to identify 
specific agents used to alter the preload, the afterload and the contractility, to the ability to correct underdamped or overdamped tubing systems.

Each individual lesson is prepared and narrated by a recognized expert in critical care, and a brief biographical sketch of the author along with a conflict of interest statement are provided at the beginning of the lesson. The slide presentation for each lesson contains about 50 slides and takes about 30-45 min to complete if left to run at its automatic pace. Two good features are a fast-forward button to allow users to skim through material with which they are already familiar, and a slide-sorter window to allow users to jump back to previous slides for review if necessary.

\section{Best feature}

A practical, step-by-step approach with appropriate grounding in cardiopulmonary physiology that can guide the novice PA catheter user through to the intermediate to advanced level.

\section{Worst feature}

The only way to really use the site is to proceed through an individual lesson, which may not be time efficient for the more advanced PA catheter user.

\section{Wish list}

A search engine that would allow users to answer specific PA catheter questions that may have arisen in the context of clinical care quickly and efficiently.

\section{Other links}

This site provides links to some, but not all, of its sponsoring/endorsing societies. Links to other PA catheter websites are not provided.

\begin{tabular}{|c|c|}
\hline & BodyRef \\
\hline FileRef & BodyRef/PDF/13054_2004_Article_2909.pdf \\
\hline
\end{tabular}




\begin{tabular}{|l|l|l||}
\hline TargetType & $:$ & OnlinePDF \\
\hline
\end{tabular}

\section{References}

30. PACEP - Pulmonary Artery Education Project. [http://www.pacep.org]

This PDF file was created after publication. 